\title{
Semiconductor Nanocrystals-Reduced Graphene Composites for the Electrochemical Detection of Carbendazim
}

\author{
Paula C. A. Santana, ${ }^{a, b}$ Jéssica B. S. Lima, ${ }^{a, b}$ Tiago B. S. Santana,${ }^{b}$ Luís F. S. Santos, ${ }^{a}$ \\ Charlene R. S. Matos, ${ }^{a}$ Luiz, P. da Costa, ${ }^{c}$ Iara F. Gimenez ${ }^{\circledR a, d}$ and Eliana M. Sussuchi ${ }^{\circledR} * a, b$
}

aPrograma de Pós-Graduação em Química, Departamento de Química,

Universidade Federal de Sergipe, 49100-000 São Cristóvão-SE, Brazil

${ }^{b}$ Laboratório de Corrosão e Nanotecnologia (LCNT),

Núcleo Regional de Competência em Petróleo, Gás e Biocombustíveis de Sergipe (NUPEG), Universidade Federal de Sergipe, 49100-000 São Cristóvão-SE, Brazil

'Instituto Tecnológico de Pesquisa de Sergipe (ITPS), 49020-380 Aracaju-SE, Brazil

${ }^{d}$ Programa de Pós-Graduação em Ciência e Engenharia de Materiais,

Universidade Federal de Sergipe, 49100-000 São Cristóvão-SE, Brazil

\begin{abstract}
A new nanocomposite based on $\mathrm{ZnCdTe}$ semiconductor nanocrystals (NCs) synthesized in situ on reduced graphene oxide ( $\mathrm{rGO}$ ) was obtained. The heterostructure was characterized using UV-Vis emission and absorption spectroscopies, which provided evidences of the growth of the nanocrystals onto the rGO matrix. To evaluate the electrochemical performance, carbon paste electrodes modified with the nanocomposite (QD-rGO/CPE) were prepared, showing high sensitivity in the electroanalytical detection of the pesticide carbendazim. Under optimal operational conditions a calibration curve was constructed with a linear behavior in the range of $9.98 \times 10^{-8}$ to $1.18 \times 10^{-5} \mathrm{~mol} \mathrm{~L}^{-1}$, with a correlation coefficient of 0.997 . The limit of detection (LOD) and the limit of quantification (LOQ) for carbendazim were $9.16 \times 10^{-8}$ and $2.78 \times 10^{-7} \mathrm{~mol} \mathrm{~L}^{-1}$, respectively. The electrode is successfully applied for the determination of carbendazim in orange juice samples.
\end{abstract}

Keywords: quantum dots, reduced graphene oxide, electrochemistry detection, carbendazim pesticide

\section{Introduction}

The nanocomposites used as modifiers of electrochemical sensors have been studied to increase the intensity of the responses/signals, improving performance in electroanalytical detections. ${ }^{1}$ In this context, materials based on nanocrystals and graphene are promising due to the improvement of their properties with potential applications in electrochemical sensors ${ }^{2}$ and photovoltaic devices, ${ }^{3}$ photocatalysis ${ }^{4}$ and photodetection. ${ }^{5}$ The nanocomposites can be obtained through the in situ growth of the semiconductor nanoparticles using graphene and its derivatives as matrix, providing an efficient electronic transport between nanomaterials with noncovalent intermolecular interactions. ${ }^{6,7}$ The stability of the nanocomposite based on nanoscale semiconductors and graphene can be improved by the strong interactions

*e-mail: esmidori@gmail.com between the constituent materials. Additionally, the receptor characteristics of the graphene dispersing the electrons in a conductive nanometric regime may promote an efficient separation of charges, making this material promising for electrochemical applications. ${ }^{89}$ In this context, the use of electrochemical methods using heterostructures is being explored not only as a characterization technique, but also in the development of analytical methodologies for detection of electroactive species. ${ }^{2,10}$ Matos et al..$^{10}$ prepared electrodes modified with $\mathrm{Cd}_{1-x} \mathrm{Mg}_{\mathrm{x}} \mathrm{Te}$ semiconductor nanocrystals and graphene-based materials. The simultaneous electrochemical determination of lidocaine and epinephrine showed high sensitivity and selectivity, using the differential pulse voltammetry technique for the detection of electroactive species.

Carbendazim (CBZ, methyl benzimidazol2-ylcarbamate) is a pesticide widely used in Brazil to avoid and eliminate a variety of diseases in agricultural processes, especially in fruits. However, owing to its 
chemical stability, carbendazim is considered a persistent pollutant in soil and water. According to Brazilian Health Regulatory Agency (Anvisa), the risk of this pesticide is considered medium with toxicological classification III, a possible carcinogen in humans with maximum residue limit of $2.62 \times 10^{-5} \mathrm{~mol} \mathrm{~L}^{-1}$ for citrus samples. ${ }^{11}$

Many analytical techniques, including capillary electrophoresis, gas or liquid chromatography method, have been applied to develop effective methods for pesticides residue analysis. ${ }^{12-16}$ Chromatography techniques operate with high sensitivity and accuracy, but they suffer from complicated pretreatment steps using toxic organic solvent and also long analysis time, and most of them require expensive equipment. The use of electroanalytical methodologies has been an alternative in the detection of pesticides, since they are cheaper techniques with easier sample preparation and rapid analysis time, in addition to high sensitivity and selectivity. ${ }^{17-21}$

In this work, we described the preparation of reduced graphene/ZnCdTe semiconductor nanocrystal composites by growing the inorganic nanocrystals in situ onto the graphene sheets, and as well as a study of electrochemical determination of carbendazim pesticide in orange juice fruit by carbon paste electrodes modified with the reduced graphene/ZnCdTe composites.

\section{Experimental}

Materials

Tellurium powder (ca. 200 mesh, 99.8\%), sodium borohydride $\left(\mathrm{NaBH}_{4}, 98 \%\right)$, cadmium chloride hydrate $\left(\mathrm{CdCl}_{2} \cdot \mathrm{H}_{2} \mathrm{O}, 98 \%\right)$, zinc chloride $\left(\mathrm{ZnCl}_{2}, 99 \%\right)$, 3-mercaptropropionic acid (MPA, 99\%), ascorbic acid (AA, $\mathrm{C}_{6} \mathrm{H}_{8} \mathrm{O}_{6}$ ) were purchased from Sigma-Aldrich. Sodium hydroxide $(\mathrm{NaOH})$ was purchased from Vetec. Graphite powder was purchased from Dinamica, potassium ferricyanide and ferrocyanide $\left(\mathrm{K}_{3}\left(\mathrm{Fe}(\mathrm{CN})_{6}\right.\right.$ and $\mathrm{K}_{4}\left(\mathrm{Fe}(\mathrm{CN})_{6}\right)$ were purchased from J. T. Baker. For Briton-Robinson (BR) buffer solutions, we used orthophosphoric acid $\left(\mathrm{H}_{3} \mathrm{PO}_{4}\right)$ from Synth. Acetic acid $\left(\mathrm{H}_{3} \mathrm{CCOOH}\right)$ was purchased from Vetec. Boric acid $\left(\mathrm{H}_{3} \mathrm{BO}_{3}\right)$ from Reagen, while analytical standard of carbendazim (purity $>98 \%$ ) was pestanal (Sigma-Aldrich). Ultrapure water was in-laboratory produced from deionized water using an ultrapure water generator device, Millipore.

\section{Preparation of graphene-based materials}

The preparation of graphene-based materials using graphite as precursor was carried out by modified Hummers method, ${ }^{10,22}$ followed by reduction with ascorbic acid to obtain reduced graphene oxide (rGO). This method was accomplished in two steps. First, $15.00 \mathrm{~g}$ of $\mathrm{KMnO}_{4}$ were mixed to $5.00 \mathrm{~g}$ graphite in a $500 \mathrm{~mL}$ beaker, which was placed in an ice bath for the dropwise addition of $100 \mathrm{~mL}$ concentrated $\mathrm{H}_{2} \mathrm{SO}_{4}$ from a buret, under vigorous stirring. After this, a black sludge was formed, the beaker was removed from the ice bath and $400 \mathrm{~mL}$ water were added to the mixture. Then the resulting solution was heated at $90{ }^{\circ} \mathrm{C}$ for $1 \mathrm{~h}$ under constant stirring, when a dark yellow suspension was formed. The mixture was centrifuged, washed 3 consecutive times with water and the solid residue collected. In the second step, the reduction of the graphene oxide prepared in the first step was carried out by mixing $1.00 \mathrm{~g}$ graphene oxide with $10.00 \mathrm{~g}$ ascorbic acid in $50 \mathrm{~mL}$ deionized water, and kept under constant stirring at room temperature for $48 \mathrm{~h}$ to yield a yellow solution of reduced graphene oxide (rGO).

Preparation of $\mathrm{ZnCdTe}$ nanocrystals in situ onto reduced graphene oxide

In the methodology described for obtaining MPA-capped ZnCdTe nanocrystals onto rGO, initially $2 \mathrm{~mL}$ of the $\mathrm{rGO}$ solution was diluted to $40 \mathrm{~mL}\left(1 \mathrm{mg} \mathrm{mL}^{-1}\right)$ with ultrapure water. The resulting solution was used as the medium for dissolving the metallic precursors $\left(\mathrm{CdCl}_{2}\right.$ and $\left.\mathrm{ZnCl}_{2}\right)$ and capping agent (MPA), adjusting pH to 9.0 with $\mathrm{NaOH}$ solution $\left(0.2 \mathrm{~mol} \mathrm{~L}^{-1}\right)$, with 1:1:2 Zn:Cd:thiol stoichiometric proportions according to our previous report of $\mathrm{Zn}_{x} \mathrm{Cd}_{1-x} \mathrm{Te}$ nanocrystals. ${ }^{23}$ Separately, a NaHTe solution was freshly prepared in a Schlenk tube under $\mathrm{N}_{2}$ atmosphere, by the addition of $0.064 \mathrm{~g}$ of Te powder and $1.50 \mathrm{~g}$ of $\mathrm{NaBH}_{4}$ in $10 \mathrm{~mL}$ of water under vigorous stirring at $40^{\circ} \mathrm{C}$ for $20 \mathrm{~min}$, until the purple suspension became colorless. After the addition of NaHTe to the reaction medium containing the metallic precursors, the solution in the round bottomed flask became immediately orange and the mixture was transferred to a Teflon-lined stainless steel reactor for hydrothermal treatment at $100{ }^{\circ} \mathrm{C}$ for $70 \mathrm{~min}$. After the hydrothermal treatment, the reaction medium was allowed to cool down to room temperature and the suspension was centrifuged at $4000 \mathrm{rpm}$ and the collected precipitate was stored in a refrigerator. An analogous experiment was carried out using ultrapure water in the absence of $\mathrm{rGO}$ for the preparation of aqueous suspension of $\mathrm{Zn}_{x} \mathrm{Cd}_{1-\mathrm{x}}$ Te nanocrystals.

\section{Modified electrodes}

Unmodified carbon paste electrodes containing 7:3 of graphite powder:mineral oil by weight were used for the 
sake of comparison. The carbon paste modified electrodes containing $\mathrm{ZnCdTe}$ quantum dots and reduced graphene oxide (QD-rGO/CPE) were prepared by mixing graphite powder:QD-rGO:mineral oil (5:2:3 ratio). The carbon paste mixture holder was constructed using a thick-walled glass tube with $0.50 \mathrm{~cm}$ internal diameter. A copper sleeve equipped with a copper wire plunger was mounted at the top of the glass tube. By rotating the sleeve, the plunger extruded a used paste layer which was sliced off to form a fresh paste surface and was made by hand-polishing on a weighing paper. The electrodes used in the experiments were stored in a refrigerator at $4{ }^{\circ} \mathrm{C}$ and the measurements were performed at room temperature.

\section{Analytical determination of carbendazim}

A $0.01 \mathrm{~mol} \mathrm{~L}^{-1}$ carbendazim stock solution was prepared using the solid dissolved in $5 \mathrm{~mL}$ of ultrapure water. The volumes suitable for electroanalytical procedure were taken from the stock solution and diluted to $10 \mathrm{~mL}$ in the electrochemical cell containing the supporting electrolyte. Carbendazim was determined with different carbon paste electrodes and analyzed by differential pulse voltammetry. All experiments were performed at room temperature.

Real samples consisting of orange fruits were purchased at a local street fair. The fruit juice was extracted with a manual extractor and, subsequently, the collected juice was centrifuged in two cycles of $4000 \mathrm{rpm}$ for $10 \mathrm{~min}$ in order to remove residues. ${ }^{19}$ The samples were stored in an amber glass bottle in the refrigerator. An aliquot of the previously calculated volume of the carbendazim stock solution was diluted in methanol and added to the extracted juice for further analysis.

\section{Characterization techniques}

UV-Vis absorption spectroscopy measurements were performed using a PerkinElmer Lambda 45 spectrophotometer at room temperature in the $200-700 \mathrm{~nm}$ range. For the characterization of photoluminescence (PL) spectroscopy, a PerkinElmer LS 55 Luminescence Spectrometer was used, exciting samples at $350 \mathrm{~nm}$. The electrochemical measurements were carried by using Autolab 100N Potentiostat/Galvanostat. Cyclic and differential pulse voltammetrics experiments were performed in a one-compartment cell using a carbon paste working electrode, a platinum wire auxiliary electrode and $\mathrm{Ag} / \mathrm{AgCl} / \mathrm{KCl}\left(3.00 \mathrm{~mol} \mathrm{~L}^{-1}\right)$ reference electrode. The experiments were performed at $25 \pm 1{ }^{\circ} \mathrm{C}$ and in borate buffer ( $\mathrm{pH}$ 9.0). The solutions were deareated with $\mathrm{N}_{2}$ flow for $15 \mathrm{~min}$ and kept under this atmosphere during the experiment. Transmission electron microscopy (TEM) images were obtained using a Jeol 2100 microscope operating at $200 \mathrm{kV}$. Samples were prepared by dropping isopropyl alcohol suspensions onto 400 mesh carbon-coated copper grids and allowing to dry under ambient atmosphere.

\section{Results and Discussion}

Description of ZnCdTe nanocrystals and graphene-based materials

The composite obtained from in situ growth $\mathrm{ZnCdTe}$ nanocrystals onto graphene-based materials was characterized by absorption and PL spectroscopy (Figure 1), as well as TEM measurements (Figure 2). Absorption and emission bands are assigned to electron transitions involving semiconductor valence and conduction bands. Both absorption and emission bands of rGO-supported $\mathrm{ZnCdTe}$ shifted to higher wavelengths compared to the aqueous colloidal $\mathrm{ZnCdTe}$. This suggests that nanocrystal growth onto rGO sheets may favor the formation of larger particles due to nanocrystal aggregation, which is confirmed by TEM images (discussed below). PL spectra evidence also a decrease in the emission intensity for rGO-supported $\mathrm{ZnCdTe}$, a behavior already reported for quantum dots grown onto graphene sheets ${ }^{10}$ related to nanocrystal to graphene charge transfer.

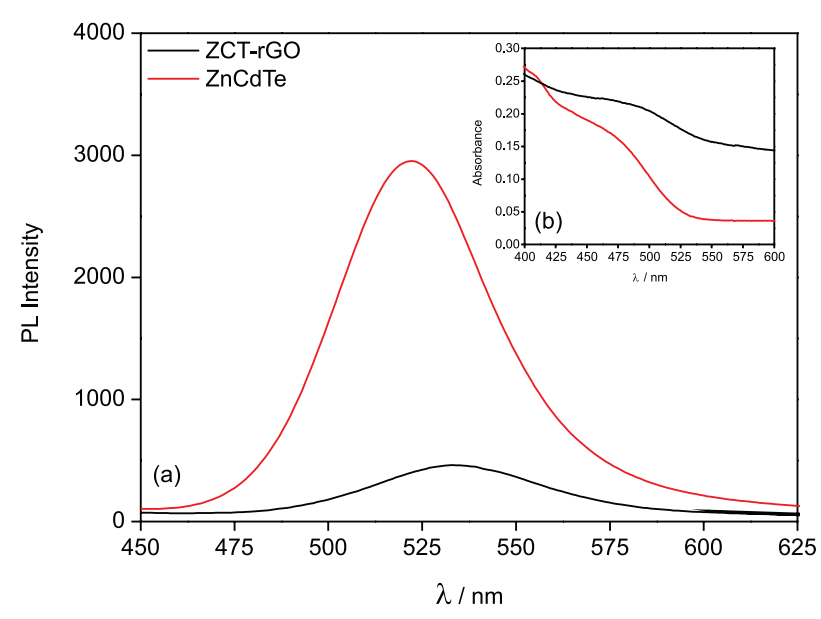

Figure 1. (a) Photoluminescence spectra $\left(\lambda_{\text {exc }} 350 \mathrm{~nm}\right)$ for $\mathrm{ZnCdTe}$ and ZnCdTe-rGO samples; (b) UV-Vis absorption spectra for ZnCdTe and ZnCdTe-rGO samples.

TEM images (Figure 2) show that rGO sample obtained here has the typical sheet morphology with folded regions and transparent layers (Figure 2a). After $\mathrm{ZnCdTe}$ growth, the graphene sheets are coated by a large amount of nanocrystals, with some degree of aggregation (Figures $2 b$ and 2c) and highly crystalline aspect, which is evidenced by 
the presence of lattice fringes (Figure 2d). The observation of the lattice fringes allows to locate each individual nanocrystal and observe the nearly spherical shapes, with diameters below $10 \mathrm{~nm}$.

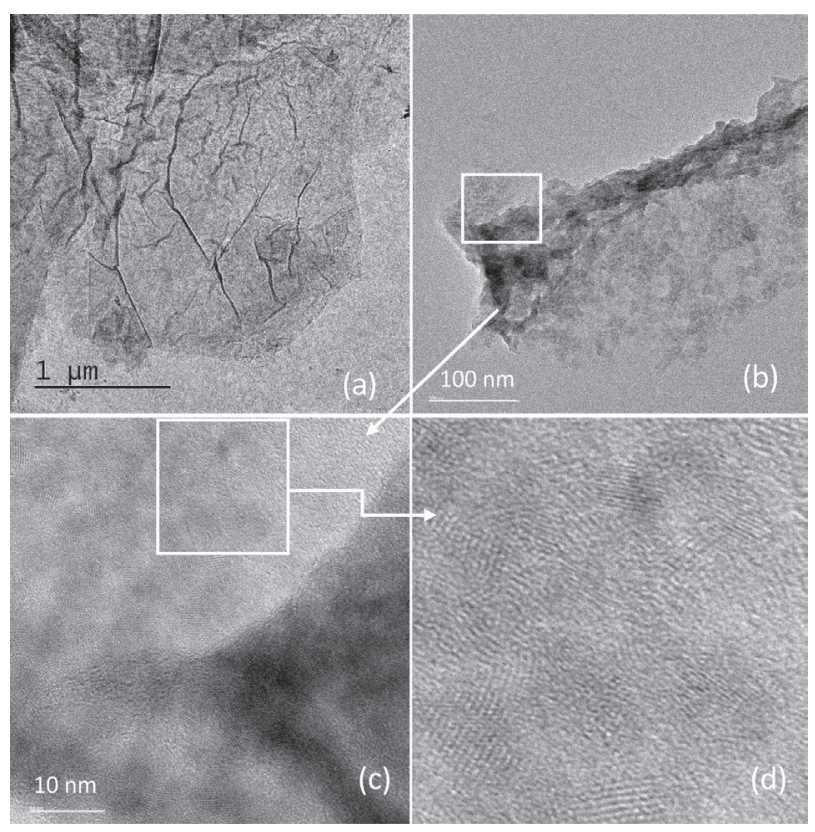

Figure 2. TEM images for rGO and ZnCdTe-rGO samples.

The electrochemical behavior of $\mathrm{ZnCdTe}$ nanocrystals grown in the presence of graphene was evaluated through the preparation of modified carbon paste electrodes. The Figure 3 shows cyclic voltammograms of the corresponding electrodes, showing that only the electrode modified with $\mathrm{ZnCdTe} /$ reduced graphene (rGO) exhibited anodic peak at $+1.08 \mathrm{~V}$ and reduction peak at $-1.25 \mathrm{~V}(v s . \mathrm{Ag} / \mathrm{AgCl})$ in the potential range studied. According to a previous report by our research group, ${ }^{23} \mathrm{ZnCdTe}$ quantum dots obtained in aqueous medium showed an anodic peak related to oxidation of tellurium species in the core of nanocrystal ${ }^{24,25}$ and a reduction peak related to the reduction of the nanocrystals, forming a relatively stable radical anion $\left(\mathrm{ZnCdTe}^{-}\right){ }^{25,26}$ The separation between anodic and cathodic peaks was measured in order to estimate the value of electrochemical band gap $\left(\Delta \mathrm{E}_{\text {elect }}=2.33 \mathrm{eV}\right)$, which is in agreement to the optical band gap estimated from the $\mathrm{PL}$ band $\left(\Delta \mathrm{E}_{\mathrm{op}}=2.32 \mathrm{eV}\right)$ and evidences the formation of the nanocrystals in the composite.

\section{Optimization of electroanalytical parameters for pesticide determination}

The influence of $\mathrm{pH}$ on the anodic differential pulse voltammograms of the QD-rGO/CPE was investigated using Briton-Robinson buffer over the $\mathrm{pH}$ 5.0-8.0 range.

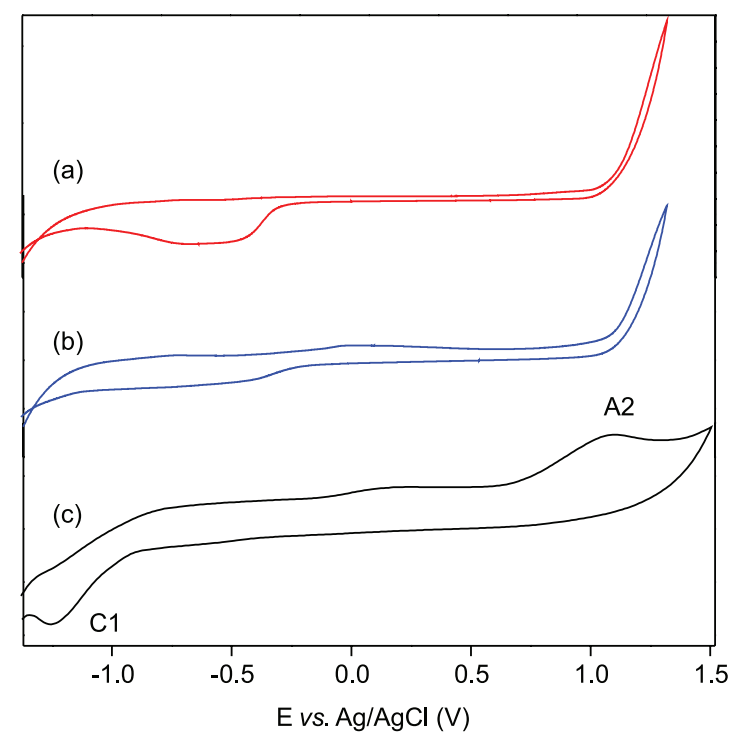

Figure 3. Cyclic voltammograms of carbon paste electrodes with different modifications: (a) bare; (b) rGO; (c) QD-rGO in borate buffered $(\mathrm{pH}=9.0)$, scan rate $50 \mathrm{mV} \mathrm{s}^{-1}$.

Figure 4 shows the presence of an intense and well defined oxidation peak in a slightly acidic condition $(\mathrm{pH}=5.0)$. Considering that the $\mathrm{p} K_{\mathrm{a}}$ value of carbendazim is 4.20 , the net electrical charge in carbendazim molecule is $\mathrm{pH}$-sensitive. Thus, under acidic conditions, that molecule is converted into its soluble salt, i.e., the deprotonated form, which favors the oxidation process. Figure S1 (Supplementary Information (SI) section) shows that a decrease of the analytical signal is observed at $\mathrm{pH}=6.0$, a phenomenon that can be attributed to the beginning of the degradation effect generating electroactive products that decrease the electroanalytical response. This behavior was also evidenced in the other $\mathrm{pH}$ values $(7.0,7.5,8.0)$, due to the broadening of the anodic peak caused by the overlapping of carbendazim oxidation peaks with those of the electroactive species formed. ${ }^{27,28}$

The electrode composition effect was studied by varying the amount of the composite in the graphite powder:mineral oil mixture. The anodic peak currents increased with increasing amount of QD-rGO composite up to $20 \%(\mathrm{~m} / \mathrm{m})$, for amounts higher than $20 \%$ the peak currents decreased significantly (Figure S2, SI section). Scan rate optimization evidenced that $20 \mathrm{mV} \mathrm{s}^{-1}$ was a suitable choice due to the better analytical signal profile. The influence of the accumulation time on the oxidation response of carbendazim showed that the oxidation peak currents increased with extending accumulation time from 0 to $300 \mathrm{~s}$. For longer times, a marked decrease in peak current was evidenced, indicating the saturation of the electrode surface. ${ }^{24-29}$ Therefore, the time of $300 \mathrm{~s}$ was selected in further experiments. 
Electrochemical behaviors of the modified electrodes by determination of carbendazim pesticide

The performance of the modified carbon paste electrode (QD-rGO/CPE) towards the determination of carbendazim pesticide was studied by differential pulse voltammetry. Figure 4 shows the voltammogram characteristic of the bare carbon paste electrode (curve a), reduced graphene oxide (curve b) and QD-rGO (curve c) modified electrodes in presence of carbendazim under optimized conditions. The oxidation of carbendazim was evidenced by the presence of a well-defined peak at $+0.88 \mathrm{~V}(\mathrm{Ag} / \mathrm{AgCl})$ using QD-rGO/CPE, showing that the detection of carbendazim is enhanced by the presence of quantum dots and reduced graphene modification.

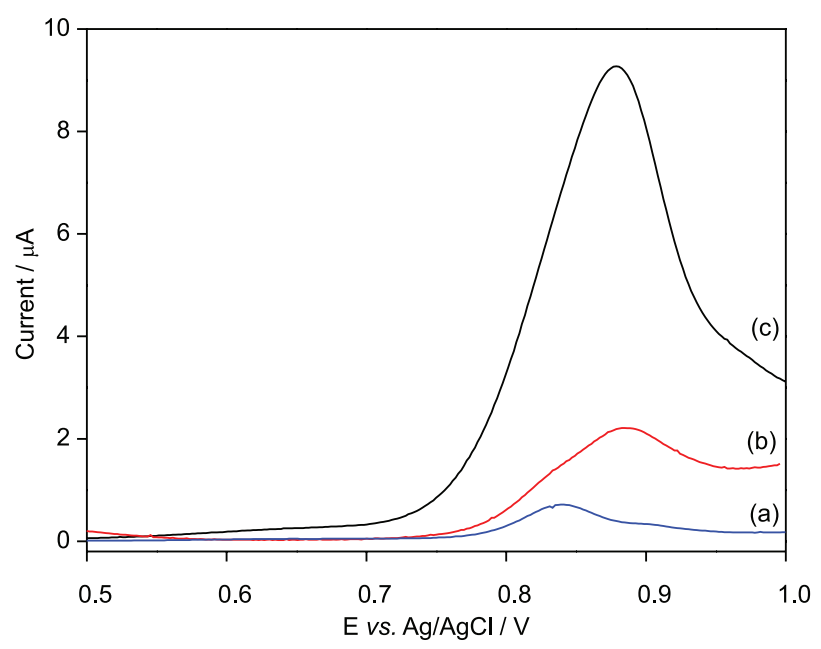

Figure 4. Differential pulse voltammograms of carbon paste electrodes with different modifications: (a) bare; (b) rGO; (c) QD-rGO in BritonRobinson buffer solution $(\mathrm{pH}=5.0)$ containing $5.0 \times 10^{-5} \mathrm{~mol} \mathrm{~L}^{-1}$ carbendazim, scan rate $20 \mathrm{mV} \mathrm{s}^{-1}$.

Carbendazim was quantified using QD-rGO/CPE modified electrodes by differential pulse voltammetry (DPV). Figure 5 displays the voltammograms under optimized conditions for carbendazim measured with

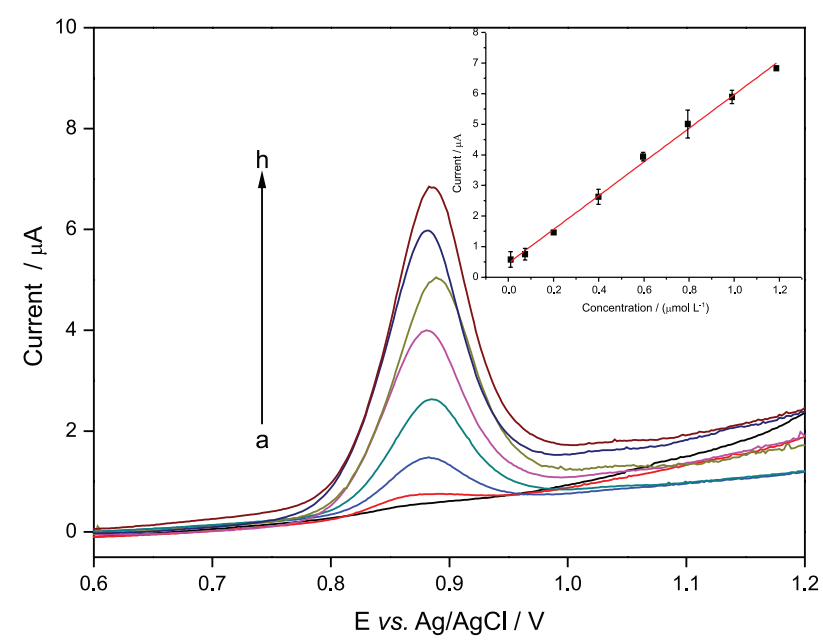

Figure 5. Differential pulse voltammograms measured with QD-rGO/CPE for different carbendazim concentrations (a-h): 0.01, $0.74,2.00,3.98,5.96,7.94,9.90,11.80 \mu \mathrm{mol} \mathrm{L}^{-1}$ in Briton-Robinson $(\mathrm{pH}=5.0)$, scan rate $20 \mathrm{mV} \mathrm{s}^{-1}$ and analytical curve from the anodic peak currents (inset).

QD-rGO/CPE and the respective analytical curve (inset).

The observed anodic peak currents were proportional to the concentration of the corresponding carbendazim solutions (Figure 6). A linear relationship between the anodic peak currents and carbendazim concentration was observed from $9.98 \times 10^{-8}$ to $1.18 \times 10^{-5} \mathrm{~mol} \mathrm{~L}^{-1}$, with linear fitting equation as $\mathrm{I}_{\mathrm{pa}}=5.51[\mathrm{CBZ}]+4.62 \times 10^{-6}$, where $\mathrm{I}_{\mathrm{pa}}$ is the anodic peak current and [CBZ] is concentration of carbendazim, with a linear correlation coefficient $\left(\mathrm{R}^{2}\right)$ of 0.997 , detection limit (LOD) $9.16 \times 10^{-8} \mathrm{~mol} \mathrm{~L}^{-1}$ and quantification limit (LOQ) $2.78 \times 10^{-7} \mathrm{~mol} \mathrm{~L}^{-1}$. According to the report published by Anvisa, ${ }^{11}$ the maximum residue limit allowed for carbendazim is $5.0 \mathrm{mg} \mathrm{kg}^{-1}$ $\left(2.62 \times 10^{-5} \mathrm{~mol} \mathrm{~L}^{-1}\right)$. Therefore, the LOD and LOQ values of carbendazim using the modified electrode demonstrate that it is possible to detect this pesticide in real orange juice samples. Additionally, the results obtained here were comparable to other modified electrodes (Table 1). The increased sensitivity in the detection of CBZ using the

Table 1. Comparison analytical characteristics of some electrochemical sensors for carbendazim detection

\begin{tabular}{lcc}
\hline Modified electrode & Technique & Limit of detection $/\left(\mathrm{mol} \mathrm{L}^{-1}\right)$ \\
\hline GO-MWNTs/GCE & differential pulse voltammetry & $5.0 \times 10^{-9}$ \\
Amberlite-XAD2-GNS/GCPE & adsorptive stripping voltammetry & $3.1 \times 10^{-9}$ \\
Tricresyl phosphate/CPE & adsorptive stripping voltammetry & $3.0 \times 10^{-7}$ \\
SiO $_{2}-\mathrm{MWCNT/GCE}$ & square wave voltammetry & $5.6 \times 10^{-8}$ \\
Silicon OV-17/CPE & adsorptive stripping voltammetry & $4.8 \times 10^{-8}$ \\
QD-rGO/CPE & differential pulse voltammetry & 30 \\
\hline
\end{tabular}

GO-MWNTs/GCE: graphene oxide dispersed multi-walled carbon nanotubes composite modified glassy carbon electrode; Amberlite-XAD2-GNS/GCPE: graphene nanosheets and amberlite XAD-2 modified glassy carbon paste electrode; $\mathrm{SiO}_{2}-\mathrm{MWCNT} / \mathrm{GCE}$ : silica/multiwalled carbon nanotubes/glassy carbon electrode; Silicon OV-17/CPE: graphite electrode modified with silicone OV-17; QD-rGO/CPE: carbon paste modified electrodes with quantum dots and reduced graphene oxide. 
electrode modified (QD-rGO/CPE) can be attributed to the synergistic effect of nanocrystals and reduced graphene oxide. The distribution of the $\mathrm{ZnCdTe}$ nanocrystals in the rGO sheet promotes an increase in the effective area of the electrode, increasing the amount of CBZ on the surface of the modified electrode. This effect and the conductivity of the hybrid material increase the electron transfer rate between electrode and the analyte facilitating the oxidation of the pesticide. The use of this electrode is also justified by the ease of preparation and regeneration of the electrode surface, allowing the rapid reading of the analyses in possible applications as a portable electrode.

An interference study of other electroactive species (ascorbic and citric acid, both commonly found in fruit juices) on the proposed method in the determination of carbendazim was also carried out. The selectivity of the QD-rGO/CPE was evaluated by DPV measurements in $5.0 \times 10^{-5} \mathrm{~mol} \mathrm{~L}^{-1}$ carbendazim solution with $0.1: 1 ; 1: 1$; 10:1 of possible interfering species: $\mathrm{CBZ}$ ratios under the optimized conditions. The selectivity of the modified electrode for carbendazim detection in the presence of interfering species, showing only a slight increase of oxidation currents of carbendazim in the presence of interfering species. The repeatability of the method was evaluated in three different concentration ranges $(5.96,7.94$ and $\left.9.90 \mu \mathrm{mol} \mathrm{L}^{-1}\right)$ in triplicate. The results reveal that the electrode presented satisfactory repeatability, indicating the accuracy of the method with relative standard deviations of $3.7,7.6$ and $8.7 \%$, respectively.

\section{Real samples analysis}

QD-rGO/CPE was used in the determination of CBZ in real orange juice samples. The experiments were performed by adding an aliquot of the $5 \%(\mathrm{v} / \mathrm{v})$ sample to the supporting electrolyte in the presence of $10 \% \mathrm{MeOH}$ to minimize matrix effects. Successive additions of the standard carbendazim solution were performed and the data show an increase in the anodic peak current proportional to the added analyte amount (Figure 6), according to the linear equation: $\mathrm{I}_{\mathrm{pa}}(\mathrm{A})=1.51 \times 10^{-6}+1.04[\mathrm{CBZ}]\left(\mathrm{mol} \mathrm{L}^{-1}\right)$, $\mathrm{R}^{2}=0.993$. By linear extrapolation, the amount of carbendazim present in the sample was found to be

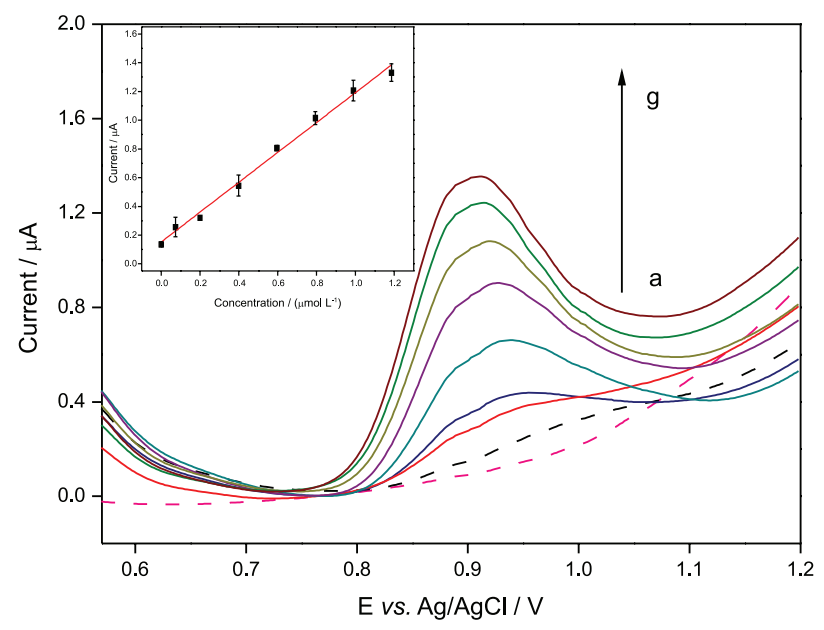

Figure 6. Differential pulse voltammograms do QD-rGO/CPE in absence of matrix (--, in red); in the presence of $5 \%$ orange juice (--, in black) and different concentrations of CBZ 0.74, 2.00, 3.98, 5.96, 7.94, 9.90, $11.80 \mu \mathrm{mol} \mathrm{L}^{-1}(\mathrm{a}-\mathrm{g})$ in Briton-Robinson $(\mathrm{pH}=5.0)$, scan rate $20 \mathrm{mV} \mathrm{s}^{-1}$. Inset: analytical curve from the anodic peak currents.

$29.1 \mu \mathrm{mol} \mathrm{L}-1$ (5.56 ppm) in orange juice, indicating the presence of the pesticide in the sample. The recovery of the amounts of carbendazim added were calculated. The results obtained are shown in Table 2, with satisfactory recovery ranging from $93.3-99.7 \%$, evidencing the viability in the proposed method.

\section{Conclusions}

The semiconductor nanocrystals obtained in situ onto the reduced graphene oxide matrix exhibited absorption and emission bands shifted to longer wavelengths compared to free nanocrystals, evidencing a synergic effect. The electrochemical characterization of the composite showed oxidation and reduction peaks typical of nanocrystals, demonstrating an efficient incorporation. The presence of semiconductor nanocrystals on the reduced graphene oxide facilitated an electron transfer between the electrode and solution, leading to an improved electrochemical response. An electrochemical method was developed for the determination of carbendazim, presenting LOD and LOQ values comparable to other sensors, which demonstrates the viability of its application for analyte detection. The proposed method was used in the analysis of

Table 2. Recovery study performed adding standard solutions of carbendazim diluted orange juice samples

\begin{tabular}{lcccc}
\hline $\begin{array}{l}\text { [CBZ] electrochemistry cell / } \\
\left.(\mu \mathrm{mol} \mathrm{L})^{-1}\right)\end{array}$ & {$\left[\mathrm{CBZ}\right.$ added / $\left(\mu \mathrm{mol} \mathrm{L}{ }^{-1}\right)$} & $\begin{array}{c}\text { [CBZ] expected value / } \\
\left(\mu \mathrm{mol} \mathrm{L}^{-1}\right)\end{array}$ & $\begin{array}{c}\text { [CBZ] found / } \\
\left(\mu \mathrm{mol} \mathrm{L}^{-1}\right)\end{array}$ & Recovery / \% \\
\hline \multirow{3}{*}{1.46} & 0.74 & 2.20 & $2.19 \pm 0.07$ & 99.7 \\
& 5.96 & 7.42 & $7.27 \pm 0.17$ & 98.0 \\
\hline
\end{tabular}

CBZ: carbendazim. 
carbendazim residues in a real orange juice sample, leading to results above the values allowed by Anvisa $\left(5 \mathrm{mg} \mathrm{kg}^{-1}\right.$, $\left.2.62 \times 10^{-5} \mathrm{~mol} \mathrm{~L}^{-1}\right)$.

\section{Supplementary Information}

Supplementary data are available free of charge at http://jbcs.sbq.org.br as PDF file.

\section{Acknowledgments}

Authors are grateful to Brazilian funding agencies CNPq, CAPES and FAPITEC/SE for financial support, to LNLS for TEM measurements, to CLQM (Center of Chemistry Laboratories Multi-users) from Federal University of Sergipe for the analysis support and Prof Dr Sandro Navickiene for material support.

\section{References}

1. Marín, S.; Merkoçi, A.; Electroanalysis 2012, 24, 459.

2. Cincotto, F. H.; Moraes, F. C.; Machado, S. A. S.; Chem. - Eur. J. 2014, 20, 4746.

3. Guo, C. X.; Yang, H. B.; Sheng, Z. M.; Lu, Z. S.; Song, Q. L.; Li, C. M.; Angew. Chem. 2010, 122, 3078.

4. Xiang, Q.; Yu, J.; Jaroniec, M.; Chem. Soc. Rev. 2012, 41, 782.

5. Lu, Z.; Guo, C. X.; Yang, H. B.; Qiao, Y.; Li, C. M.; J. Colloid Interface Sci. 2011, 353, 588.

6. Katsukis, G.; Malig, J.; Schulz-drost, C.; Leubner, S.; Jux, N.; Guldi, D.; ACS Nano 2012, 6, 1915.

7. Chang, H.; Lv, X.; Zhang, H.; Li, J.; Electrochemistry 2010, $12,483$.

8. Cao, A.; Liu, Z.; Chu, S.; Wu, M.; Ye, Z.; Cai, Z.; Chang, Y.; Wang, S.; Gong, Q.; Liu, Y.; Adv. Mater. 2010, 22, 103.

9. Markad, G. B.; Battu, S.; Kapoor, S.; Haram, S. H.; J. Phys. Chem. 2013, 117, 20944.

10. Matos, C. R. S.; Souza Jr., H. O.; Santana, T. B. S.; Candido, L. P. M.; Cunha, F. G. C.; Sussuchi, E. M.; Gimenez, I. F.; Microchim. Acta 2017, 184, 1755.

11. http://portal.anvisa.gov.br/programa-de-analise-de-registro-deagrotoxicos-para, accessed in February 2019.

12. Paranthaman, R.; Sudha, A.; Kumaravel, S.; Am. J. Biochem. Biotechnol. 2012, 8, 1 .
13. Xiaowen, D.; Xianfeng, C.; Weijun, K.; Yinhui, Y.; Meihua, Y.; RSC Adv. 2015, 5, 86163.

14. Oskotskaya, E. R.; Gribanov, E. N.; Saunina, I. V.; J. Anal. 2017, 72, 206.

15. Boeris, V.; Arancibia, J. A.; Olivieri, A. C.; Anal. Chim. Acta 2014, 814, 23.

16. Kim, K.; Park, D.; Kang, G.; Kim, T.; Yang, Y.; Moon, S.; Choi, E.; Ha, D.; Kim, E.; Cho, B.; Food Chem. 2016, 208, 239.

17. Trojanowicz, M.; Electroanalysis 2002, 14, 19.

18. Khare, N. G.; Dar, R. A.; Srivastava, A. K.; Electroanalysis 2015, 27, 1915.

19. Petroni, J. M.; Lucca, B. G.; Fogliato, D. K.; Ferreira, V. S.; Electroanalysis 2016, 28, 1362.

20. Razzino, C. A.; Sgobbi, L. F.; Canevari, T. C.; Cancino, J.; Machado, S. A. S.; Food Chem. 2015, 170, 360.

21. Gou, Y.; Guo, S.; Li, J.; Wang, E.; Dong, S.; Talanta 2011, 84, 60.

22. Hummers Jr., W. S.; Offeman, R. E.; J. Am. Chem. Soc. 1958, $80,1339$.

23. Matos, C. R. S.; Candido, L. P. M.; Souza, H. O.; Costa, L. P.; Sussuchi, E. M.; Gimenez, I. F.; Mater. Chem. Phys. 2016, 178, 104.

24. Bae, Y.; Myung, N.; Bard, A. J.; Nano Lett. 2004, 4, 1153.

25. Poznyak, S. K.; Osipovich, N. P.; Shavel, A.; Talapin, D. V.; Gao, M.; Eychmuller, A.; Gaponik, N.; J. Phys. Chem. B 2005, 109, 1094.

26. Haram, S. K.; Quinn, B. M.; Bard, A. J.; J. Am. Chem. Soc. 2001, 123, 8860.

27. Li, Y.; Jiang, Y.; Mo, T.; Zhou, H.; Li, Y.; Li, S.; J. Electroanal. Chem. 2016, 767, 84.

28. Ya, Y.; Wang, T.; Xie, L.; Zhu, L.; Li, T.; Ning, D.; Yan, F.; Anal. Methods 2015, 7, 1493.

29. Luo, S.; Wu, Y.; Gou, H.; Ionics 2013, 19, 673.

30. Ashrafi, A. M.; Dordevic, J.; Guzsvány, V.; Svancara, I.; TrticPetrovic, T.; Purenovic, M.; Vytras, K.; Int. J. Electrochem. Sci. 2012, 7, 9717.

31. Hernandez, P.; Ballesteros, Y.; Galan, F.; Hernandez, L.; Electroanalysis 1996, 8, 941.

Submitted: October 25, 2018

Published online: February 12, 2019 